University of Nebraska - Lincoln

DigitalCommons@University of Nebraska - Lincoln

P. F. (Paul Frazer) Williams Publications

Electrical \& Computer Engineering, Department

October 1970

\title{
Raman Scattering from Localized Vibrational Modes in GaP
}

D. T. Hon

University of Southern California, University Park, Los Angeles, California

W. L. Faust

University of Southern California, University Park, Los Angeles, California

W. G. Spitzer

University of Southern California, University Park, Los Angeles, California

P. F. Williams

University of Nebraska - Lincoln, pfw@moi.unl.edu

Follow this and additional works at: https://digitalcommons.unl.edu/elecengwilliams

Part of the Electrical and Computer Engineering Commons

Hon, D. T.; Faust, W. L.; Spitzer, W. G.; and Williams, P. F., "Raman Scattering from Localized Vibrational Modes in GaP" (1970). P. F. (Paul Frazer) Williams Publications. 30.

https://digitalcommons.unl.edu/elecengwilliams/30

This Article is brought to you for free and open access by the Electrical \& Computer Engineering, Department of at DigitalCommons@University of Nebraska - Lincoln. It has been accepted for inclusion in P. F. (Paul Frazer) Williams Publications by an authorized administrator of DigitalCommons@University of Nebraska - Lincoln. 


\title{
Raman Scattering from Localized Vibrational Modes in GaP $\dagger$
}

\author{
D. T. Hon, W. L. Faust, W. G. Spitzer, and P. F. Williams \\ Department of Physics and Department of Electrical Engineering, University of Southern California, \\ University Park, Los Angeles, California 90007 \\ (Received 11 August 1970)
}

\begin{abstract}
High-frequency localized vibrational modes of impurities in a III-V compound have been observed by Raman scattering. Three lines from the GaP samples closely correspond to some local modes previously reported in infrared studies, and depolarization measurements tend to confirm their proposed assignments. We describe several attractive features of this method for the study of semiconductor impurities.
\end{abstract}

It is well known ${ }^{1}$ that a small concentration of impurities introduced into a perfect crystal will have little effect on the vibrational dispersion branches. But in some cases there may appear vibrational modes ${ }^{1,2}$ lying outside of the allowed frequency range of the perfect crystal. These are called localized vibrational modes, or local modes, because the mode energy is spatially concentrated near the defect site.

Following the observation of the local mode of nitrogen ${ }^{3}$ in GaP in luminescence, infrared $a b-$ sorption was observed for a number of impurities in several different III-V semiconductors. ${ }^{4-11}$ To the best of our knowledge, this is the first report of Raman scattering from high-frequency local modes in a III-V compound. Other related system types from which Raman scattering has been reported include mixed crystals, ${ }^{12-14}$ the $U$ center in alkaline-earth halides, ${ }^{15}$ and the $F$ center in alkali halides ${ }^{16}$; only the second belongs to a well-defined high-frequency localized vibrational excitation. The systems we discuss here are found to give generous signal levels with impurity concentration as low as $10^{17} \mathrm{~cm}^{-3}$. The four GaP ingots used in this study were chosen from a set used in some previously reported infrared work. ${ }^{10}$ We shall continue the labeling scheme established in Ref. 10 (ingots Nos. 1, 2, 3, 4, 5, 6), and extend it with further numerals for additional samples (see Table I). They are compensated polycrystals prepared by the vertical Bridgman technique; for the de- 


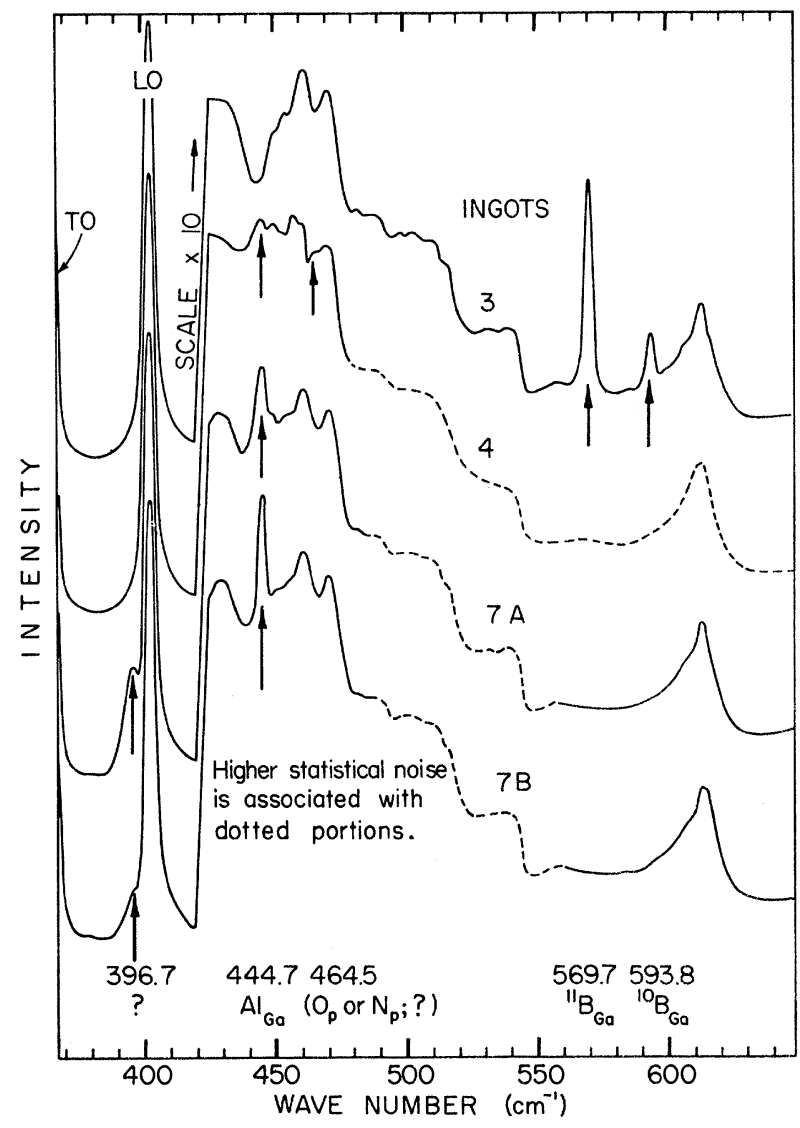

FIG. 1. Raman spectra from ingots $3,4,7 \mathrm{~A}$, and $7 \mathrm{~B}$, showing lines attributed to local modes in GaP, without a polarizer. All lines have essentially the same depolarization $(\sim 0.75)$. The general background and unlabeled structure common to all traces is due to second-order Raman scattering typical of pure GaP.

tails of preparation, see Ref. 10 and Blum, Chicotka, and Bischoff. ${ }^{17}$

In this experiment, the linearly polarized beam from a krypton laser $(\lambda=5681.9 \AA$, power $\simeq 10$ $\mathrm{mW})$ was focused onto a cooled sample $\left(T \simeq 100^{\circ} \mathrm{K}\right)$. Spectra were taken at $90 \mathrm{deg}$, with provision for polarization analysis. A Spex model 1400 tandem spectrometer and a liquid-nitrogencooled model ITT FW 130 photomultiplier were used.

While the signal-to-noise ratio was generally very favorable, the interpretation of the data has been handicapped by the background from secondorder Raman scattering as well as fluorescence associated with certain impurities. Steps are being taken to alleviate these difficulties.

Figure 1 shows the Raman spectra from the various samples. We have omitted ingot No. 1, which did not give any significant information because of strong fluorescence. Three lines agree with local modes observed previously by infrared absorption. Table I compares the results from the two methods. The lines at 593.8 and $569.7 \mathrm{~cm}^{-1}$ are believed to be due to ${ }^{10} \mathrm{~B}_{\mathrm{G}}$ and ${ }^{11} \mathrm{~B}_{\mathrm{Ga}}$, respectively, where $X_{Y}$ designates isotope $X$ located on a $Y$ site; and the one at 444.7 to $\mathrm{Al}_{\mathrm{Ga}}$. Our depolarization measurements tend to corroborate these substitutional assignments. A line at 464.5 is too weak to be certain, although the same sample did yield such a line in the infrared spectrum, where it was tentatively assigned to $\mathrm{O}_{\mathrm{p}}$ or $\mathrm{N}_{\mathrm{p}}$. No gap modes have been observed in our spectra thus far. We studied two samples from ingot No. 7, which was heavily doped with $\mathrm{Al}$ : One was taken from a slice $6 \mathrm{~cm}$ from the melt, the other $1.5 \mathrm{~cm}$. For each there is a strong line at $396.7 \mathrm{~cm}^{-1}$ on the low-frequency shoulder of the LO phonon. The identity of this line has yet to be determined, but its intensity and location between the LO and TO lines raise some interesting speculations.

Previous to this work, the assignment of the pair of lines 593.8 and $569.7 \mathrm{~cm}^{-1}$ to ${ }^{10} \mathrm{~B}_{\mathrm{Ga}}$ and ${ }^{11} \mathrm{~B}_{\mathrm{G}}$ had been somewhat inconclusive, not only because these values are substantially different from those obtained by the simple formula of Dawber and Elliott, ${ }^{18}$ but also because of the possibility of a defect pair of the type $X_{G_{a}}-Y_{\text {interstitial }}$. But such a defect pair would have symmetry $C_{3 v}$ (instead of $T_{d}$ as for the proposed case of ${ }^{10} \mathrm{~B}_{\mathrm{G}} \mathrm{a}$ and ${ }^{11} \mathrm{~B}_{\mathrm{Ga}}$ ), and it would give rise to local modes belonging to $A_{1}$ (two modes) and $E$ (two modes each doubly degenerate), as shown in Table II. For each of our lines the depolarization is found to be $\sim 0.75$ : This rules out the $A_{1}$ modes (which would give a value $\leqslant 0.016$ ). The two lines could also be due to the two modes belonging to $E$ (which would indeed give the observed depolarization); but this would require that the two $A_{1}$ modes, which are both Raman- and infraredactive by group-theory considerations, be so weak as to be absent in both spectra. Furthermore, the intensity ratio $~ 1.4$ is approximately equal to that of the natural isotopic abundances of boron. The same intensity ratio was also obtained between the corresponding lines in the infrared absorption spectra reported in Refs. 10 and 11. The assignment of the lines 593.8 and $569.7 \mathrm{~cm}^{-1}$ to ${ }^{10} \mathrm{~B}_{\mathrm{Ga}}$ and ${ }^{11} \mathrm{~B}_{\mathrm{G}}$ have thus become essentially conclusive. (There is still, in principle the possibility of a boron atom in an interstitial site with symmetry $T_{d}$. But such a defect is extremely unlikely for an isoelectronic atom, by experience and by theoretical considerations. In particular, the frequencies should be much 
Table I. Local mode frequencies $\left(\mathrm{cm}^{-1}\right)$ and relative intensities (in parentheses).

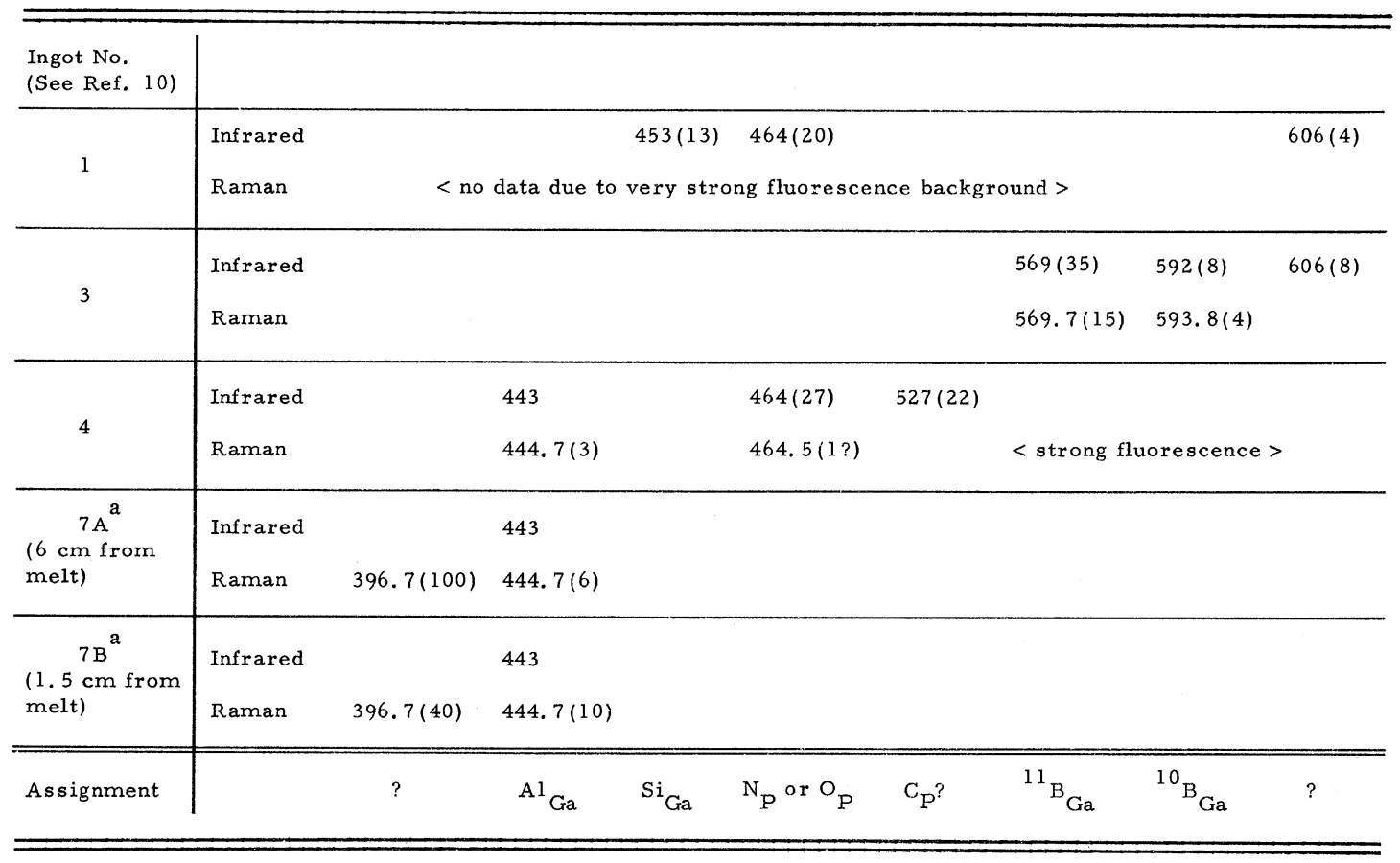

${ }^{a}$ Ingot 7, from which samples $7 \mathrm{~A}$ and $7 \mathrm{~B}$ were cut, was discussed in the addendum of Ref. 10 without a label assignment, $7 \mathrm{~A}, \sim 6 \mathrm{~cm}$ from the melt; $7 \mathrm{~B}, \sim 1.5 \mathrm{~cm}$.

lower than those observed.)

Further effort is being made to investigate a larger variety of dopants and hosts of the III-V family, with various exciting laser frequencies, including longer wavelengths to minimize fluorescence. Attractive features of this technique include the following: (i) Spectra can convenient- ly be taken in small volumes of material; (ii) one can work with uncompensated samples in which free carriers produce excessive absorption in the infrared; (iii) one can study frequency regions where the infrared method may be infeasible due to intrinsic absorption; and (iv) it provides much more definitive information on site

Table II. Localized vibrational modes for $C_{3 v}$ and $T_{4}$ symmetries. All those are both infrared and Raman active.

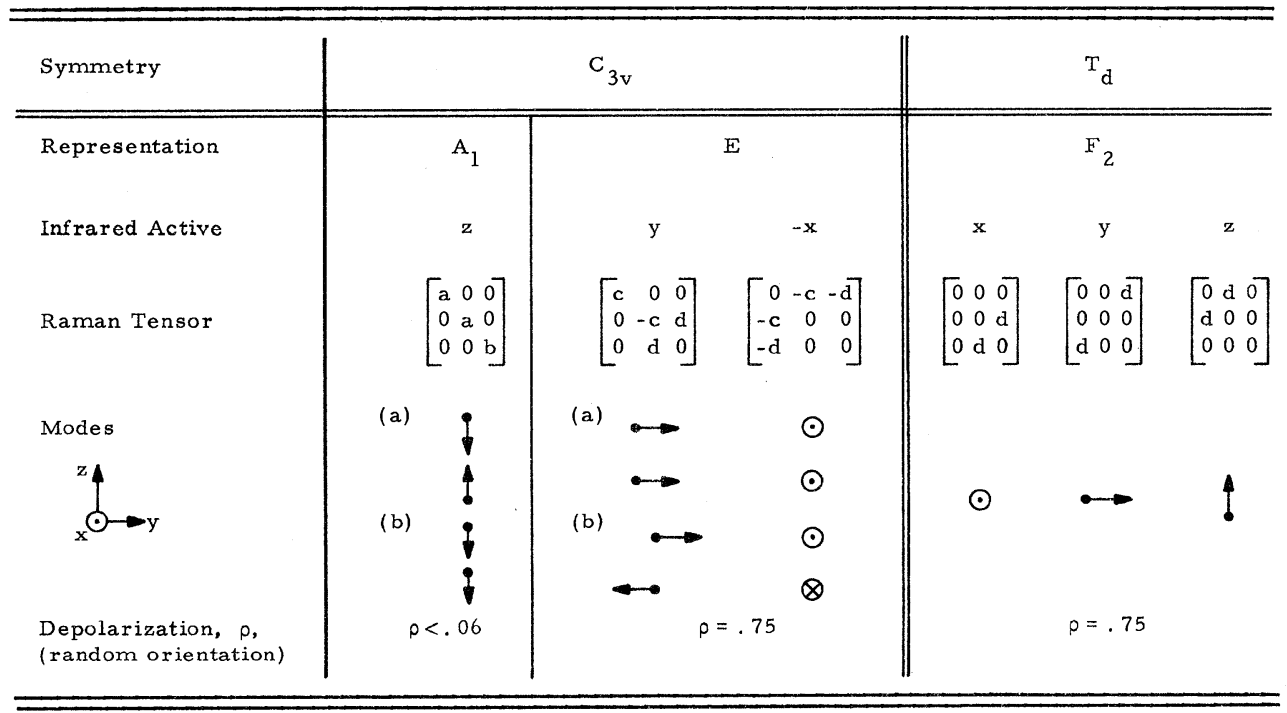


symmetry than does infrared absorption. Complementary to the EPR and infrared methods, laser Raman spectroscopy will prove to be a very useful tool in the study of impurities in semiconductors.

We wish to thank Mr. W. S. Otaguro who built the krypton laser, and Dr. S. E. Blum of IBM who grew the crystals. Gratitude is due to Professor S. P. S. Porto for many profitable discus sions and for his generosity in allowing the use of some of his laboratory facilities.

$\dagger$ Research supported by the Advanced Research Projects Agency of the Department of Defense and monitored by U. S. Army Research Office-Durham under Contract No. DAHC 04-69-C-0003. Support also was given by the Joint Services Electronics Program, monitored by the U. S. Air Force Office of Scientific Research, under Grant No. AFOSR-69-1622.

${ }^{1}$ A. A. Maradudin, E. W. Montroll, and G. H. Weiss, Theory of Lattice Dynamics in the Harmonic Approximation (Academic, New York, 1963).

${ }^{2}$ A. A. Maradudin, in Solid State Physics, edited by H. Ehrenreich, F. Seitz, and D. Turnbull (Academic, New York, 1966), Vol. 18, p. 273, and Vol. 19, p. 1.

${ }^{3}$ D. G. Thomas and J. J. Hopfield, Phys. Rev. 150,
680 (1966).

${ }^{4}$ W. Hayes, Phys. Rev. 138, A1277 (1965).

${ }^{5}$ O. G. Lorimor and W. G. Spitzer, J. Appl. Phys. $\underline{38}$, 3008 (1967).

${ }^{6}$ W. G. Spitzer, J. Phys. Chem. Solids 28, 33 (1967).

${ }^{7}$ W. Hayes, Phys. Rev. Lett. 13,275 (1964).

${ }^{8}$ W. G. Spitzer and W. Allred, Appl. Phys. Lett. 12, 5 (1968).

${ }^{9}$ M. Levy and W. G. Spitzer, J. Appl. Phys. $\underline{39}, 1914$ (1968).

${ }^{10}$ W. G. Spitzer, W. Allred, S. E. Blum, and R. J. Chicotka, J. Appl. Phys. 40, 2589 (1969).

${ }^{11}$ W. Hayes, H. F. MacDonald, and C. T. Sennett,

J. Phys. C: Proc. Phys. Soc., London 2, 2402 (1969).

${ }^{12}$ N. D. Strahm and A. L. McWhorter, Solid State

Commun. $\underline{6}$, No. 10, xvi (1968).

${ }^{13}$ O. Brafman et al., Phys. Rev. Lett. 19, 1120 (1967).

${ }^{14}$ I. F. Chang and S. S. Mitra, Phys. Rev. 172, 924 (1968)。

${ }^{15}$ R. T. Harley, J. A. Harrington, and C. T. Walker, Bull. Amer. Phys. Soc. 15, 297 (1970).

${ }^{16} \mathrm{~J}$. M. Worlock and S. P. S. Porto, Phys. Rev. Lett. 15, 697 (1965).

${ }^{17}$ S. E. Blum, R. J. Chicotka, and B. K. Bischoff, J. Electrochem. Soc. 115, 324 (1968).

${ }^{18} P_{\circ} G_{\circ}$ Dawber and R. J. Elliott, Proc. Roy. Soc., Ser. A 273, 222 (1963).

${ }^{19}$ R. Loudon, Advan. Phys. 13, 423 (1964). 